\title{
Vinski kultivari vinove loze u Hercegovini
}

\section{Sažetak}

Prema povijesnim podatcima vinova loza se na području Hercegovine uzgajala i u vrijeme starih llira, odnosno plemena Daorsa. Danas se prema procjenama u BiH nalazi oko 4.000 hektara pod vinovom lozom. U mnoštvu vinskih kultivara lokalnog sortimenta svojom kakvoćom izdvojili su se kultivari Žilavka i Blatina. Uz Žilavku se u hercegovačkim nasadima vinove loze uzgajaju prateće sorte Bena, Krkošija i Dobrogostina, a uz Blatinu autohtoni kultivar Trnjak, kao i poznati svjetski kultivari Vranac, Merlot i Alicante Bouschet. U razdoblju nakon Domovinskog rata na području Hercegovine podižu se i nasadi vinove loze u kojima su zastupljeni i ostali, cijenjeni kultivari kao što su Syrah, Chardonnay, Cabernet sauvignon, Souvignon blanc, Muscat ottonel, Graševina i brojni drugi.

Ključne riječi: vinova loza, područje Hercegovine, kultivari Žilavka i Blatina

\section{Uvod}

Vinova loza je najznačajnija i jedna od najzastupljenijih kultura u poljoprivrednoj proizvodnji Hercegovine. U Bosni i Hercegovini preko 95 \% površina pod vinovom lozom nalazi se upravo u južnim krajevima Hercegovine. Zbog povoljnih agroekoloških odnosno klimatskih i zemljišnih uvjeta područje Hercegovine je izrazito pogodno za uzgoj vinove loze i na temelju klimatskih elemenata ovaj rajon je svrstan u zonu $C_{2}$. Hercegovački vinogradarski tereni se nalaze na nadmorskoj visini od 8 do $650 \mathrm{~m}$. U pogledu konfiguracije lokaliteti za uzgoj vinove loze su različiti. Ima ih na ravnim položajima u dolini rijeke Neretve, na potezu od Mostara do Gabele (općina Čapljina), i na uzvišenim platoima Brotnja (općina Čitluk) i Dubrava (područje između općina Čapljina i Stolac). Najveći broj vinograda nalazi se na blagim nagibima od $5^{0}-12^{\circ}$. U mostarskom vinogorju nasadi vinove loze zasnivaju se na različitim tipovima tala: crvenicama, regosolima, aluvijalnim nanosima i smeđem tlu na krečnjaku (Gašpar i Kolovrat 2013).

U vinogradarskom rajonu Sjeverna Bosna također polako oživljava vinogradarstvo i proizvodnja vina. Uglavnom se uzgajaju kontinentalne sorte kao npr. Graševina, Rajnski rizling, Merlot i Cabernet sauvignon (Ivanković i Kolega, 2016). Međutim, prema procjenama u BiH se nalazi svega 4.000 ha pod ovom kulturom. Razlozi takvog činjeničnog stanja mogu se tražiti u rascjepkanosti posjeda, sve evidentnijem nedostatku radne snage, zahtjevnosti i sve manjoj isplativosti proizvodnje. Nasadi vinove loze u Hercegovini uglavnom su mali, prosječne veličine $0,2-0,3$ ha. Svega $4 \%$ vinogradara uzgaja vinovu lozu na proizvodnim površinama većim od $1 \mathrm{ha}$. Osim toga, mali i rascjepkani posjedi otežavaju primjenu poljoprivrednih strojeva te se mnogi agrotehnički radovi moraju izvoditi ručno, uz veliko učešće ljudskog rada. 
Posljednjih godina evidentan je problem s pronalaskom sezonske radne snage bez koje je nemoguće izvesti važne zahvate u nasadima vinove loze kao što su rezidba, pljevidba, berba i sl. Posebno je to izraženo posljednjih nekoliko godina kada su se zbog boljeg ekonomskog učinka iskusni sezonski radnici preorijentirali na poslove vezano za sadnju i berbu smilja, dok mlade generacije egzistenciju pronalaze u nekim drugim poslovima ili $u$ inozemstvu.

\section{Vinski kultivari zastupljeni u uzgoju na području Hercegovine}

Žilavka je gospodarski značajna, najzastupljenija bijela visokokvalitetna autohtona sorta Hercegovine. Ime je vjerojatno dobila zbog svoje otpornosti i mogućnosti uzgoja u različitim proizvodnim uvjetima (žilava-žilavka) ili pak po tankim žilicama tj. provodnim snopovima koji se u punoj zriobi uočavaju u bobicama grožđa. Žilavka s pratećim kultivarima Benom i Krkošijom zauzima dominantno mjesto u sortimentu hercegovačkih vinograda (40-50 \%). Trs odlikuje bujan i uspravan rast. List je često peterodijelan, srednje veličine i svijetlozelene boje. Naličje lista je prekriveno dlačicama. Peteljka lista je srednje duljine i prekrivena je rijetkim dlačicama. Cvijet je morfološki i funkcionalno hermafroditan zbog čega ne dolazi do nepotpune oplodnje koja se manifestira pojavom rehuljavosti grozda. Bobice su okrugle, srednje veličine, zlatnožute ili zelenkasto-žute boje. Peteljka grozda je čvrsta. Grozdovi su piramidalnog oblika, srednje krupni i težine 150-200 grama. Dozrijeva u trećem razdoblju (III. epoha). U godinama s ranijom vegetacijom u okolici Mostara i na položajima uz Neretvu berba se obavlja znatno ranije i to početkom rujna dok se na povišenim položajima na području Brotnja (općina Čitluk) i Dubrava (područje između općina Čapljina i Stolac) s berbom započinje polovicom rujna. U godinama s kasnijom vegetacijom berba se odgađa za 10-tak dana. Sorta ima relativno dobar prinos i odlikuje ju redovita rodnost. Pogodna je za uzgoj na niskom, srednje visokom ili visokom trsu. Dobre prinose ostvaruje pri kratkoj rezidbi na dva pupa premda podnosi mješovitu i dugu rezidbu. Vrlo dobro uspijeva na južnim ekspozicijama gdje dominiraju srednje duboka i krševita tla umjerene vlažnosti. Bolje podnosi uzgoj na suhom tlu u odnosu na niske terene i vlažna zemljišta. U praksi susrećemo dva varijeteta Žilavke koja se razlikuju po boji bobica i prema stupnju zbijenosti grozda, a koje proizvođači nazivaju žuta i zelena Žilavka. Žilavka kojoj vinogradari daju prefiks žuta osim zlatnožute boje pokožice bobica, formira i sitnije bobice grozda koji je prilično rastresit. Žilavka koju nazivaju zelena, osim zelenkasto-žute

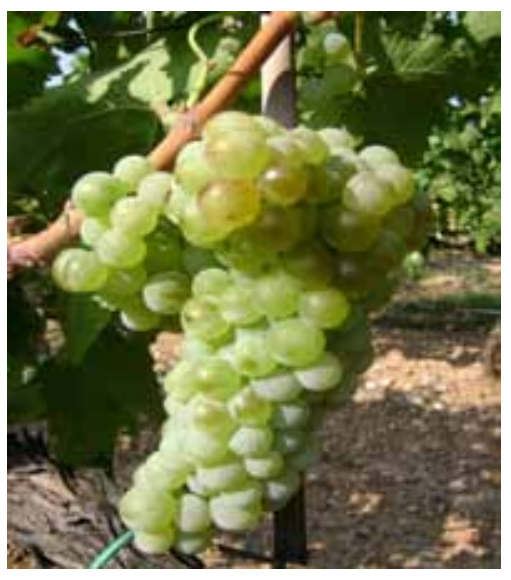

boje pokožice bobica ima izrazito zbijene grozdove zbog čega je podložna pojavi i razvoju sive plijesni. Nije poznato imaju li varijeteti odlike klona ili se radi o jednoj te istoj Žilavci kod koje se javljaju određene morfološke razlike pod utjecajem različitih agroekoloških uvjeta uzgoja. Sadržaj šećera u moštu kreće se od 20-24\%, a ukupnih kiselina 5-6 $\mathrm{g} \mathrm{l}^{-1}$. Sadržaj alkohola varira od 11 do 14 vol\%. Od kultivara Žilavka proizvode se kvalitetna vina, a s odabranih lokaliteta odnosno vinograda vrhunska vina, s dodatkom do $15 \%$ Krkošije i Bene. Vino odlikuje skladan odnos alkohola i kiselina te karakterističan miris. Vino je pitko i ima žutozelenu boju.

Slika/Figure 1: Žilavka Izvor/Source: Autoru/Authors 
Krkošija je autohtoni bijeli vinski kultivar Hercegovine. Sazrijeva u trećem razdoblju kao i Žilavka. Zbog anomalija u građi cvijeta ima neredovitu oplodnju i slabije zametanje bobica. Formira grozdove stožastog oblika i prosječne težine 100-200 grama. Trs je srednje bujan. Odgovara mu kratka rezidba, a podnosi i mješovitu. List je peterodijelan do sedmerodijelan, s dubokim urezima. Uzgaja se na propusnim tipovima tala s dovoljno vlažnosti. Prilično je izbirljiva u pogledu tla i ne podnosi sušu. Odgovaraju joj crvenice s područja Čitluka, Čapljine i Ljubuškog gdje ostvaruje zavidne rezultate u pogledu rodnosti. Rodnost joj je ipak manja u odnosu na Žilavku jer je osjetljiva na vremenske prilike u vrijeme cvatnje. To je posebno izraženo kod nekih tipova Krkošije. Naime, Krkošija predstavlja smjesu nekoliko tipova koji se vrlo različito ponašaju u pogledu rodnosti. Stoga je kod ovog kultivara potrebno pronaći najrodniji tip koji potom treba reproducirati, a sve

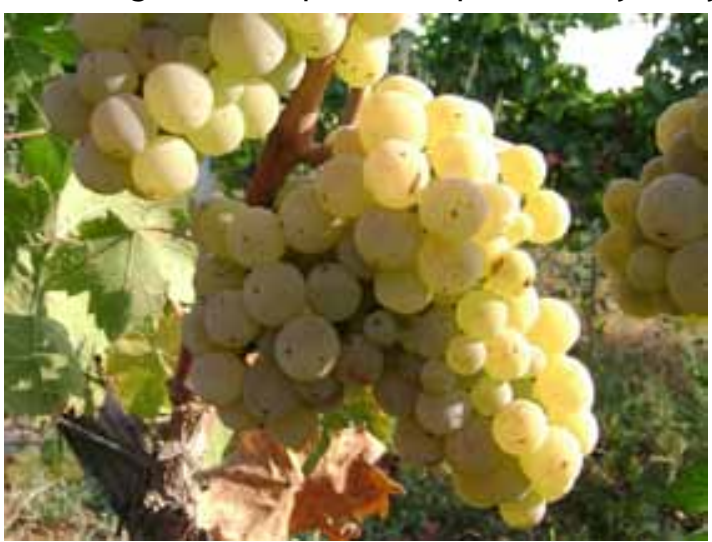
ostale tipove uništiti zbog njihove defektnosti. Krkošija se u odnosu na Žilavku odlikuje većim sadržajem kiselina u grožđu i u vinu. Vino od Krkošije brzo se bistri i lako njeguje, ali mu nedostaje potrebna harmoničnost. Žutozelenkaste je boje, jako u alkoholu i na okusu dovoljno kiselo, s dobrim ekstraktom ali bez potrebne arome. Međutim, u kupaži sa Žilavkom i Benom mogu se postići kvalitetna i dobra vina.

Slika/Figure 2: Krkošija Izvor/Source: Autoru/Authors

Bena je lokalna bijela vinska sorta koja je redoviti pratitelj Žilavke u hercegovačkim nasadima vinove loze. Zbog nedovoljne kakvoće grožđa iznimno rijetko se pravi vino samo od ove sorte. Dozrijeva u prvoj polovici rujna. Uz kratku rezidbu urod joj je dobar. Prosječna težina grozda iznosi oko 130-180 grama. Grozd je rastresit, piramidalnog oblika i nalazi

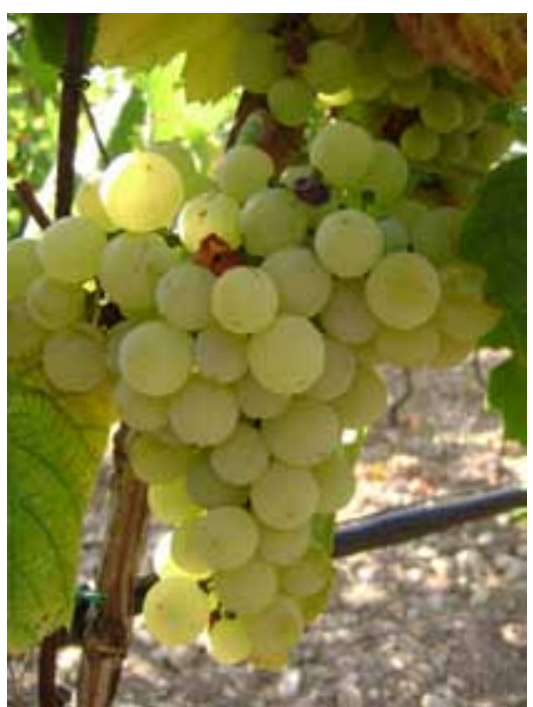
se na kratkoj, odrvenjeloj peteljci. Bobice grozda su velike, okruglastog ili duguljastog oblika, zlatnožute boje pokožice. Bena je izrazito nezahtijevna sorta u pogledu uzgoja na oskudnim tlima i nepovoljnim položajima. Prilično je otporna prema plamenjači i pepelnici. U odnosu na Žilavku njen mošt sadržava više kiselina, ali uvijek manje u odnosu na Krkošiju. Zbog većeg sadržaja kiselina dobar je dodatak vinu (do $5 \%$ ) od Žilavke. Kao pratećoj sorti prednost se u nasadima uvijek daje Krkošiji, izuzev na lošijim tipovima tala i nepovoljnim položajima koji više pogoduju uzgoju izdržljive Bene. Mošt sadržava 16-22 \% šećera i 4,9$7,8 \mathrm{~g} \mathrm{l}^{-1}$ ukupnih kiselina. Koristi se i za konzumaciju u svježem stanju (kao zobatica).

Slika/Figure 3: Bena Izvor/Source: Autoru/Authors 
Dobrogostina je lokalna bijela sorta koja se uzgaja na području Hercegovine. Uz Krkošiju i Benu uzgaja se kao prateća sorta u nasadima Žilavke. Trs joj je srednje bujan

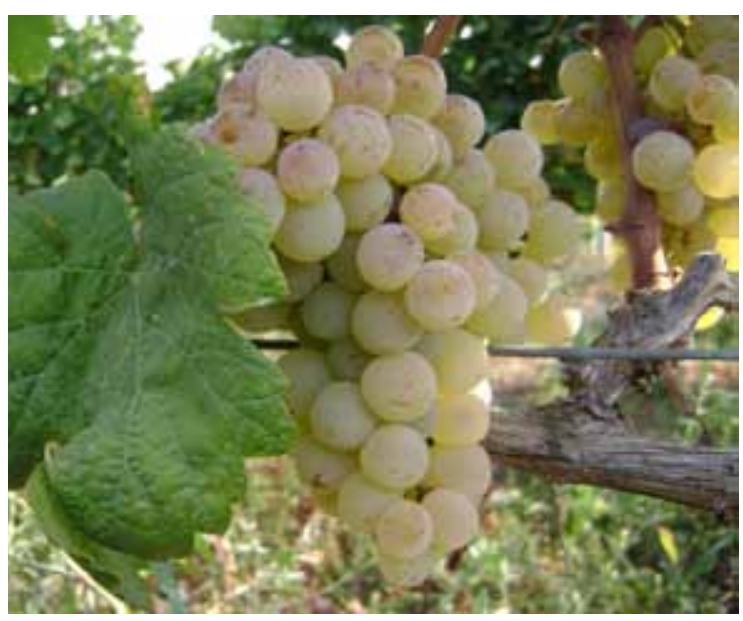
i izrazito rodan. Sorta dozrijeva tjedan dana prije Žilavke. Formira velike, srednje zbijene grozdove piramidalnog oblika. Bobice su velike, tanke pokožice i žutozelene boje. Zbog tanke pokožice u kišnim godinama dolazi do pucanja vrlo sočnih bobica pa se pojavljuje i razvija siva plijesan. Sorta je slabo otporna na plamenjaču. Osim za kupažu vina sorta se koristi za konzumaciju u svježem stanju. Nema veći gospodarski značaj i uzgaja se sporadično.

Slika/Figure 4: Dobrogostina Izvor/Source: Autoru/Authors

Blatina je autohtona sorta Hercegovine. Od crnih vinskih kultivara vodeća je u pogledu spravljanja prvoklasnih crnih vina, crvene rubin boje. Blatina je defektna sorta koja ima funkcionalno ženske cvjetove i koja se sama ne može oploditi. Zbog te činjenice treba je saditi i uzgajati u asocijacijama s drugim sortama (mješoviti nasadi) koje imaju dvospolne cvjetove i čija se cvatnja podudara s cvatnjom Blatine. Dobre prateće sorte i oprašivači Blatine su Trnjak, Vranac, Plavka, Alicante bouschet, Gamay, Merlot a u posljednje vrijeme sve više se sadi u kombinaciji sa Žilavkom. Za uzgoj Blatine važno je odabrati odgovarajući položaj i tip tla. Uzgoj Blatine na ravničarskim terenima nije poželjan jer je praksa pokazala kako zbog slabe cirkulacije zraka redovito dolazi do problema s njenom oplodnjom. Dijelom se to može premostiti prorjeđivanjem listova oko cvata kako bi se time poboljšala aeracija i kako bi se omogućio nesmetan prijenos polena s procvjetalih dvospolnih sorata u nasadu. Blatina je vrlo izbirljiva prema tipu tla na kojem se uzgaja. Iznimno je važna sposobnost tla da zadrži vlagu tijekom vegetacije iz razloga što u izrazito sušnim uvjetima uzgoja dolazi do neželjene pojave smežuravanja bobica grozda i rapidnog opadanja prinosa. Ukoliko u vremenskom razdoblju od šaranja do pune zrelosti Blatina nema na raspolaganju dovoljne količine vlage, u uvjetima žarkih i sušnih ljetnih mjeseci podbacuje u prinosu i formira tzv. čereze tj. sasušene bobice grozda iz kojih se preradom može dobiti iznimno malo grožđanog soka. S druge strane ne odgovara joj uzgoj na suviše vlažnim položajima, a iznimno je važno da tijekom cvatnje Blatine ne bude obilnih, dugotrajnih padalina. Osjetljiva je na ekstremno visoke temperature praćene jakim dnevnim insolacijama koje u pojedinim godinama mogu prouzročiti palež i sušenje grozdova (Rotim, 2007). Blatina dozrijeva u trećem razdoblju. Formira grozdove srednje veličine čija prosječna težina pri normalnoj oplodnji iznosi 200-300 grama. Pri dobroj oplodnji pojedini grozdovi mogu težiti i preko 500 grama. Pri slaboj oplodnji prosječna težina grozdova iznosi svega 50-100 grama. Grozdovi su konusnog ili piramidalnog oblika, rastresiti ili zbijeni u ovisnosti od uspješnosti oplodnje. Bobice su nejednake veličine, pretežno srednje velike, okrugle s tankom pokožicom tamnoplave do crne boje. Trs je bujan i reže se kratko na reznike ili mješovito na rodne reznike i lucnjeve (poželjno je ostavljati i lucanj u slučaju 


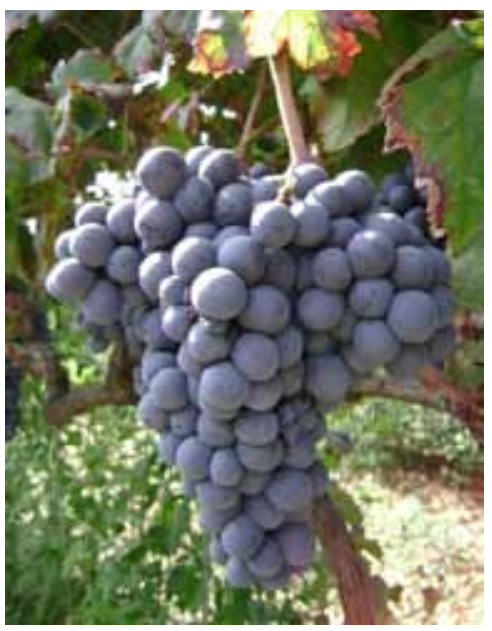

pojave rehuljavosti). Na određenim položajima postignuti su vrlo dobri rezultati rezidbom na lucnjeve. Blatina je osjetljiva prema plamenjači i pepelnici. Mošt sadržava 18-23,5 \% šećera i 6-7 $\mathrm{g} \mathrm{l}^{-1}$ ukupnih kiselina. Sadržaj alkohola, izuzetnih godina, može biti 13-15 vol\%. Vino je tamnocrvene boje, aromatično i vrlo ugodnog okusa.

\section{Slika/Figure 5: Blatina}

Izvor/Source: Autoru/Authors

Trnjak predstavlja autohtonu hercegovačku sortu koja je osim u Hercegovini zastupljena u uzgoju u Dalmatinskoj zagori. Podrijetlo joj nije dovoljno istraženo. Na području općina Grude i Imotski ovu sortu nazivaju i Rudežuša. Zbog dobre kakvoće grožđa posljednjih godina sve više se uzgaja u Hercegovini. Osim u čistim nasadima zastupljena je u mješovitim nasadima kao prateća sorta koja je dobar oprašivač Blatine. Osim toga, zamjetno je kako vinogradari napuštaju manje kvalitetnu sortu Plavku (Plavinu), a na njenim položajima sve češće uzgajaju kultivar Trnjak. Prvi veći nasad Trnjka u Hercegovini zasniva se 1969. godine u Ljubuškom na površini od 13 ha (lokalitet Otok). U okolici Mostara 2004. i 2006. godine također se podižu nasadi Trnjka na površinama od nekoliko hektara. Dozrijeva u trećem razdoblju. Oplodnja je dobra, kao i prirod koji je redovit. Formira kratke, zbi-

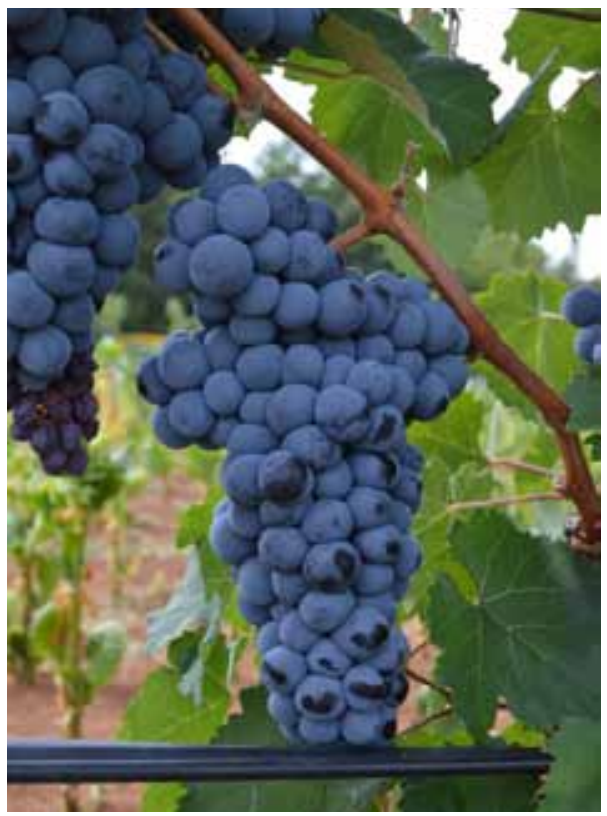
jene grozdove srednje veličine i prosječne težine oko 150-200 grama. Bobica je okruglasta, srednje veličine i izrazito plavocrne boje. Pokožica je debela i prekrivena maškom. Srednje je bujna sorta koja podnosi sve uzgojne oblike, ali kod rezidbe treba voditi računa o opterećenju trsa. Može se rezati kratko, a podnosi i mješoviti rez. Listovi su peterodijelni s tri isječka, zelene boje i srednje veličine. Lice lista je golo, dok je naličje prekriveno vunastim dlačicama. Sorta je otporna na plamenjaču i pepelnicu, a osjetljiva na sunčane ožegotine. Mošt sadržava 20-24 \% šećera i 6-8 g $\mathrm{I}^{-1}$ ukupnih kiselina. Vino je tamne rubin crvene boje, dobre konzistencije. U prošlosti se grožđe isključivo prerađivalo sa ostalim sortama, a od 2009. godine u Hercegovini se proizvodi sortno vino Trnjak.

Slika/Figure 6: Trnjak Izvor/Source: Autoru/Authors 
Alicante Bouschet je crna vinska sorta izrazito obojanog soka i spada u kategoriju bojadisera. Potječe iz Francuske gdje je nastala 1855. godine križanjem sorti Petit Bouchet i Grenache. U Hercegovini ovu sortu nazivaju Kambuša. Srednje je bujna sorta čiji je cvijet

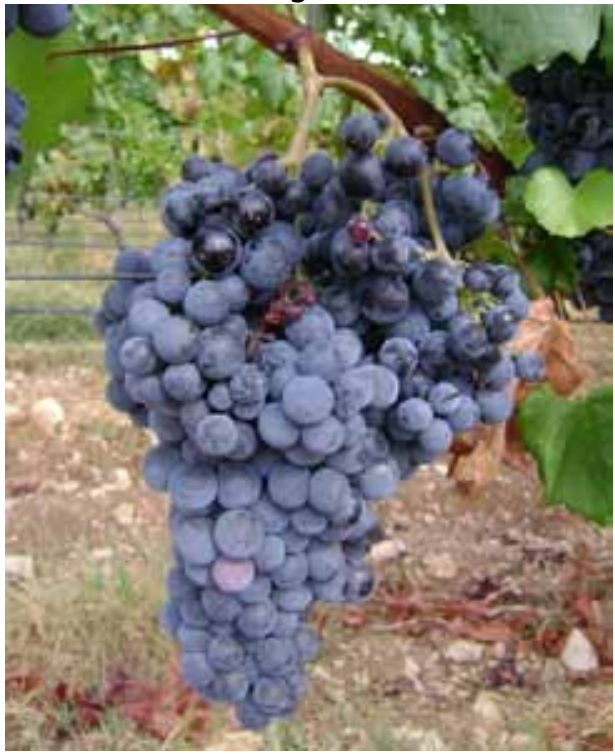
funkcionalno hermafroditan. Oplodnja je normalna i redovita. Listovi su mali, slabo urezani dok je liska uvrnuta prema naličju lista koje je prekriveno dlačicama. Formira srednje velike grozdove prosječne težine 150-200 grama. Bobice su srednje veličine, okruglaste s debelom, čvrstom pokožicom. Pokožica je plavocrne boje i prekrivena je maškom. Sazrijeva krajem trećeg razdoblja. Velike je i redovite rodnosti. Prateća je sorta bojadiser koja se zbog intenzivne boje koristi u kupažama vina u svrhu popravke boje vina drugih crnih sorti. Karakterizira je dobra otpornost prema plamenjači, pepelnici i sivoj plijesni. Mošt je izrazito obojan i sadržava 18-22 \% šećera i 6,5-9 $\mathrm{g} \mathrm{l}^{-1}$ ukupnih kiselina.

Slika/Figure 7: Alicante Bouschet Izvor/Source: Autoru/Authors

Vranac je autohtona sorta Crna Gore koja je u uzgoju zastupljena u Hercegovini. Zbog blizine matične zemlje, sličnih klimatskih uvjeta i postizanja dobrih proizvodnih rezultata Vranac se prilično ustalio u vinogradarskoj proizvodnji Hercegovine. Kultivar dozrijeva u prvoj dekadi rujna. Trs je vrlo bujan, a pogoduju mu i kratka i duga rezidba. List je velik, peterodijelan i oštro nazubljen. Cvijet je funkcionalno dvospolan, a oplodnja je normalna i redovna. Formira grozdove srednje veličine i prosječne težine 150-200 grama. Grozdovi

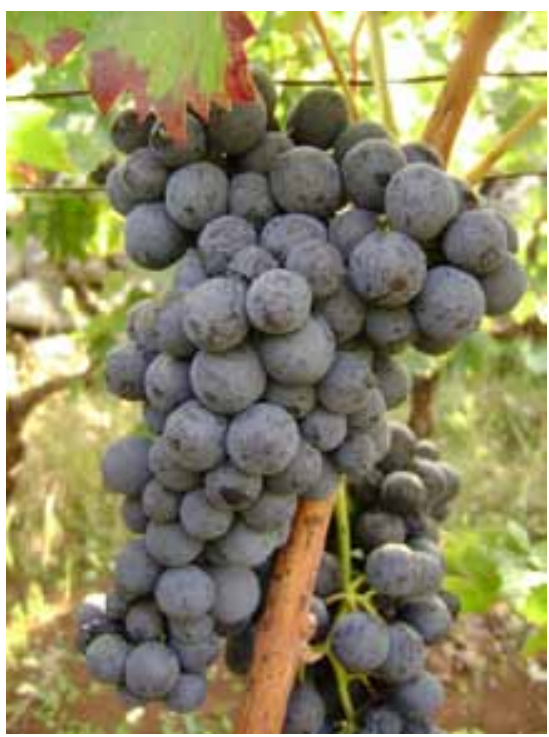
se nalaze na dugačkoj peteljci. Bobice su ovalnog oblika i srednje krupnoće. Pokožica je tanka, crnoplave boje, bogata obojanim tvarima i prekrivena je maškom. Ostvaruje visoke prirode. Srednje je osjetljiva sorta prema plamenjači i pepelnici. Sadržaj šećera u moštu varira od 18 do $24 \%$ dok sadržaj ukupnih kiselina iznosi 6-8 $\mathrm{gl}^{-1}$. Od Vranca se dobiva visokokvalitetno i kvalitetno crno vino, harmonično i ugodno osvježavajućeg okusa. Blage kiseline i punoća vina daju optimalan sklad jačine i pitkosti. U odnosu na ostale crne sorte Vranac u Hercegovini zahtjeva nešto raniju berbu. Sklon je pojavi sasušenih bobica (tzv. čereza), a u slučaju prezrelosti bobice vrlo lako otpadaju s grozda pa je važno izvršiti berbu u optimalnom roku.

Slika/Figure 8: Vranac

Izvor/Source: Autoru/Authors 
Plavka je sorta nastala spontanim križanjem talijanske sorte Verdeca i Tribidraga (Lacombe i sur., 2007). U Hercegovini je nazivaju i Plavina. Uglavnom je prisutna u sortimentu starih vinograda. Trs je vrlo bujan, dozrijeva krajem trećeg razdoblja. Cvijet je funkciona-

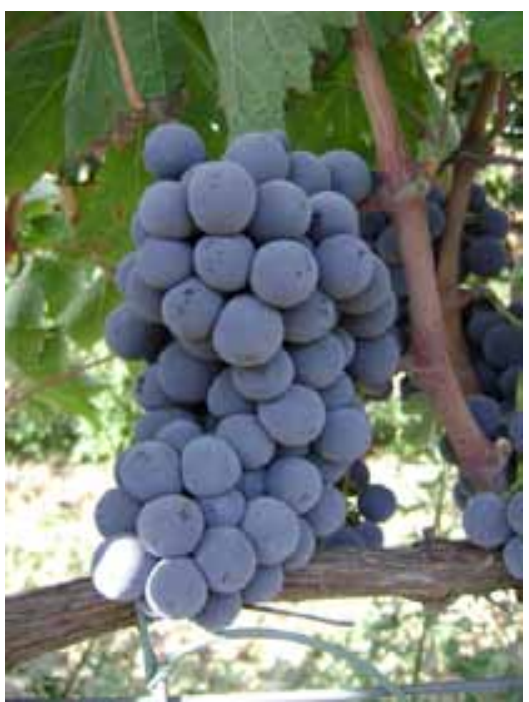
Ino hermafroditan, a oplodnja normalna i redovita. Po pitanju prinosa najsigurnija je sorta, jer redovito i obilno rađa. Formira srednje velike do velike grozdove prosječne težine 200-300 grama. Bobice su srednje veličine, okrugle s pokožicom plavocrvenkaste boje. Rezidba se obavlja na kratko rodno drvo. Dobro je otporna prema pepelnici, plamenjači i sivoj plijesni. Mošt sadržava 18-20 \% šećera i 5-7 $\mathrm{g} \mathrm{l}^{-1}$ ukupnih kiselina. Prema iskustvu pojedinih vinogradara na lokalitetu Poprati (općina Stolac) mošt Plavke uzgojene u starim nasadima redovito ostvaruje visok sadržaj $i$ šećera i kiselina. Premda se od Plavke mogu proizvesti lagana, pitka vina tamne rubin boje u praksi se rijetko proizvodi čisto sortno vino.

\section{Slika/Figure 9:Plavka}

Izvor/Source: Autoru/Authors

Merlot predstavlja jednu od najpoznatijih francuskih sorata koja se posljednjih godina intenzivnije uzgaja u Hercegovini. Bujna je sorta jakog vegetativnog potencijala. Cvijet je

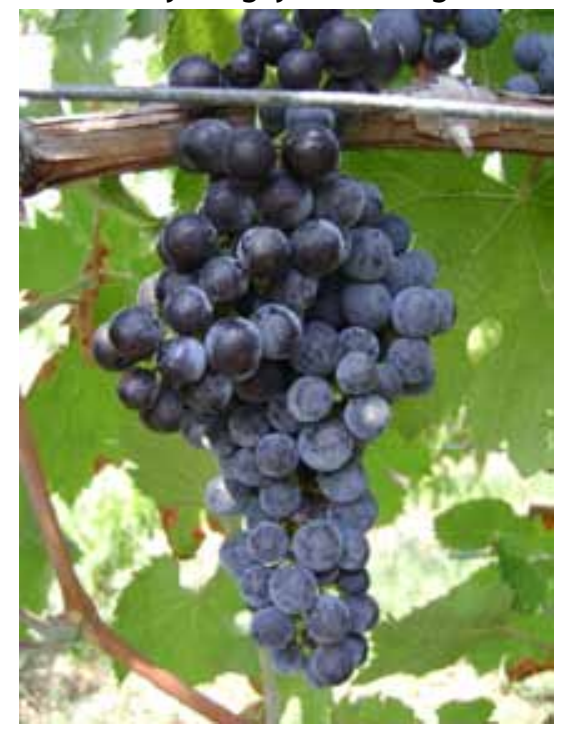
funkcionalno hermafroditan, a oplodnja normalna i redovita. Postoje klonovi u kojih je izraženo osipanje cvjetova i veća rehuljavost (Avramov, 1991). Sazrijeva u trećem razdoblju. Formira male ili srednje krupne grozdove cilindrično-konusnog oblika i prosječne težine 100-150 grama. Bobice su okrugle, sitne ili srednje velike $s$ debelom tamnoplavom pokožicom prekrivenom obilnim maškom. Rezidba se obavlja na kratke reznike i na dugo rodno drvo. Srednje je prinosna sorta. Otporna je prema sivoj plijesni i sunčanim ožegotinama. Mošt sadržava 20-24 \% šećera i 7-9 $\mathrm{g} \mathrm{l}^{-1}$ ukupnih kiselina. Vino je rubin crvene boje, harmonično i prikladno za kupažu s crvenim vinima.

Slika/Figure 10: Merlot Izvor/Source: Autoru/Authors 
